\title{
Ultraviolet Radiation over Two Lakes in the Middle and Lower Reaches of the Yangtze River, China: An Innovative Model for UV Estimation
}

\author{
Meiling Huang ${ }^{1}$, Hong Jiang ${ }^{1,2, *}$, Weimin $\mathrm{Ju}^{1}$, and Zhongyong Xiao ${ }^{1}$ \\ ${ }^{1}$ International Institute for Earth System Science, Nanjing University, Nanjing, Jiangsu, China \\ ${ }^{2}$ Zhejiang Provincial Key Laboratory of Carbon Cycling in Forest Ecosystems and Carbon Sequestration, \\ Zhejiang Agriculture and Forestry University, Hangzhou, Zhejiang, China
}

Received 24 January 2011, accepted 2 May 2011

\begin{abstract}
This study aims to explore the characteristics of ultraviolet (UV) radiation over Dong Lake (DL) and Tai Lake (TL) in the middle and lower reaches of the Yangtze River and to develop an innovative model for UV estimation under all weather conditions. The characteristic analysis of UV radiation shows distinctly hourly and monthly variations at two typical sites. The maximum values can represent the hourly UV feature, and the median and the arithmetic mean values are reasonably similar with little difference for both stations. The monthly means of hourly UV radiation range from 25.68 to $70.07 \mathrm{~kJ} \mathrm{~m}^{-2}$ for DL and between 36.00 and $92.62 \mathrm{~kJ} \mathrm{~m}^{-2}$ for TL. The monthly mean hourly UV fractions vary from $3.79 \%$ to $4.93 \%$ at DL and between $4.57 \%$ and $5.94 \%$ at TL. Comparisons on the monthly mean hourly values of UV radiation and UV fraction, the values at TL are always greater than those at DL. An innovative model is constructed based on two input parameters, namely the effect of the comprehensive attenuation factors for assumed cloud-free conditions $\left(\mathrm{CAF}_{\mathrm{UV} \text { clear }}\right)$ and the effect of the clouds $\left(\mathrm{K}_{\mathrm{g}}\right)$. $\mathrm{CAF}_{\mathrm{UV} \text { clear }}$ is derived from empirical models based on relative optical air mass and ozone. The effectiveness of the presented model is demonstrated by comparing with other two estimation models. This innovative model presents values of RMSE better than two reported models either at local place or a different locality. It indicates that this new model can provide satisfactory estimates of UV radiation at different localities other than the local place of origin where the relationships are developed.
\end{abstract}

Key words: UV radiation, Ozone, Optical air mass, Innovative estimation model, China

Citation: Huang, M., H. Jiang, W. Ju, and Z. Xiao, 2011: Ultraviolet radiation over two lakes in the middle and lower reaches of the Yangtze River, China: An innovative model for UV estimation. Terr. Atmos. Ocean. Sci., 22, 491-506, doi: 10.3319/TAO.2011.05.02.01(A)

\section{INTRODUCTION}

The study of ultraviolet (UV) radiation has received considerable attention during the past 20 years due to the link between increased UV levels at the Earth's surface and depletion of ozone in the stratosphere (Al-Aruri et al. 1988; Foyo-Moreno et al. 1998; Antón et al. 2008; Bilbao and de Miguel 2010; Escobedo et al. 2011). The detrimental impact of UV radiation on aquatic communities has been proven in freshwater environments because of high photon energy and specific absorption properties of the reacting molecules (Feister and Grewe 1995; Sommaruga and Psenner 1997; Sommaruga 2001; Carrillo et al. 2008; Koepke 2009). UV radiation can cause damage to fish larvae and juveniles,

\footnotetext{
* Corresponding author

E-mail: jianghong_china@hotmail.com
}

shrimp and crab larvae, and zooplankton and phytoplankton (Ilyas et al. 1999; Pienitz and Vincent 2000; Salo et al. 2000; Clair et al. 2001; Wrona et al. 2006a, b; Harrison and Smith 2009; Nazari et al. 2010). Some of these effects are related to the cumulative UV dose, and others may correlate with the frequency of extreme UV events or to UV doses at particular times of the year (Tarasick et al. 2003; Cordero et al. 2005). In order to quantify the biological effects of UV radiation on freshwater organisms and ecosystems, a clear knowledge of the amount of surface UV radiation and its temporal variation in freshwater environments is of great importance.

The intensity levels of surface UV radiation can be measured or estimated by various approaches (Schmalwieser et al. 2003). Great effort has been undertaken by national 
or international organizations for promoting the installation of UV monitoring networks with aim to obtain accurate data on surface UV radiation in different parts of the world, such as North America, China, Europe and Australia (Liu 2000; Gröbner et al. 2006; Bhattarai et al. 2007; Hu et al. 2007; Cui et al. 2008; Rieder et al. 2008). However, existing UV observation stations are far too low to provide sufficient UV data because of the high cost and great difficulty in maintaining the sensors that register this spectral band (Barbero et al. 2006; Janjai et al. 2010; Mateos Villán et al. 2010). Furthermore, most of these stations began operation in the last decade of the twentieth century (McKenzie et al. 1992; Zerefos et al. 1997; Gurney 1998; Bartlett and Webb 2000; Fioletov et al. 2002; Junk et al. 2007). Therefore, previous variations in UV radiation are still unknown (Junk et al. 2007). In case of China, the Chinese Ecosystem Research Network (CERN) manages 37 stations where UV radiation has been recorded continuously since August 2004 but which are insufficient to cover the whole country. Thus, suitable modeling approaches should be an appropriate alternative for estimating UV radiation values when UV observation is not available. These models can be categorized mainly into two groups (Barbero et al. 2006; Sabziparvar 2009; Láska et al. 2010): (1) radiative transfer models which describe absorption and scattering processes of UV radiation in the atmosphere; and (2) statistical models that exploit the close relationship between UV radiation and atmospheric parameters commonly measured at radiometric or climatological stations. The radiative transfer models need extensive computation and detailed information of atmospheric parameters which are generally difficult to obtain from ground-based stations. Their accuracy depends on the input parameters. Statistical models can provide good estimation of surface UV radiation, although they are more simplified compared with the radiative transfer models. Statistical models are widely used to estimate UV for specific locations.

The amount of UV radiation at any location on the earth's surface depends on geometrical factors (solar elevation angle, Earth-Sun distance, altitude and latitude), atmospheric factors (cloud coverage, aerosols, ozone column and air pollution) and ground albedo (Díaz et al. 2000). In the past few decades, many studies have been conducted to quantify these respective effects on UV radiation. Previous research concentrated mainly on the relationship between UV and an individual factor, such as global solar radiation (Feister and Grasnick 1992; Ilyas et al. 1999; Martínez-Lozano et al. 1999; Kudish and Evseev 2000; Cañada et al. 2003; Ramirez Santigosa et al. 2003; Ogunjobi and Kim 2004; Robaa 2004; den Outer et al. 2005; Escobedo et al. 2009, 2011; Sabziparvar 2009), relative optical air mass (m) (Foyo-Moreno et al. 1999; Cañada et al. 2000; Dubrovsky 2000; Murillo et al. 2003; Antón et al. 2009b) and ozone (McKenzie et al. 1991; Madronich 1992; Bais et al. 1993). Only a few studies analyze the integrated effects of main attenuation factors on UV radiation such as relative optical air mass and cloudiness (Foyo-Moreno et al. 1999; Murillo et al. 2003; Barbero et al. 2006; Mateos Villán et al. 2010); total column ozone, geometric factors and clouds (Díaz et al. 2000); global solar radiation, total ozone, dew point temperature, and snow cover (Fioletov et al. 2001); ozone, aerosols and clouds (Krzyścin et al. 2001); daily sunshine fraction, the cosine of the daily minimum SZA and the daily total ozone column (de La Casinière et al. 2002); ozone, airmass, sun-earth distance correction and solar zenith angle (Prasad and Niranjan 2005); global solar radiation, ozone and clouds (Foyo-Moreno et al. 2007); ozone and reflectivity (Antón et al. 2005); ozone and cloudiness (Antón et al. 2009b) as well as ozone and cloudiness (Láska et al. 2010). However, the amounts of UV radiation at ground level are also modulated by other attenuation factors, such as air pollution in polluted areas, which have a certain effect on the UV radiation. Since all attenuation factors are generally combined and act necessarily together, it is difficult to determine the role of each factor separately. But studies on quantifying the resulting effects of all the attenuation factors on UV radiation remain rare.

The middle and lower reaches of Yangtze River in China are rich in shallow freshwater lakes (Yao et al. 2009). The intensity of aquaculture has increased dramatically in freshwater lakes in this region over the past few decades (Xiao et al. 2010). The annual yield of aquatic products accounts for about $2 / 3$ of the national total and plays an important role in the national economy. UV radiation change has an influence on aquatic communities, so it is very significant and useful to study the characteristics of UV radiation in this region; however, studies are still insufficient to fully account for UV radiation in a freshwater environment of this region (Hu et al. 2007). The objectives of the present study are to analyze UV radiation characteristics over two typical lakes in this region and to develop an innovative model for estimating UV, which is applicable for all weather conditions. The model is aimed at quantifying the resulting effects of all the attenuation factors on UV radiation. Table 1 shows a symbol list in this text.

\section{MATERIALS AND METHODS}

\subsection{Study Area}

The middle and lower reaches of the Yangtze River are characterized by a typical East Asian monsoon climate with a hot and wet summer and cold and dry winter. The annual mean air temperature is about $15-20^{\circ} \mathrm{C}$ with a minimum temperature of $0-4^{\circ} \mathrm{C}$ in the winter and a maximum of 27 $-30^{\circ} \mathrm{C}$ in the summer. Annual total precipitation is about $1000-1400 \mathrm{~mm}$, mainly in summer. There are 651 lakes with areas larger than $1 \mathrm{~km}^{2}$ and 18 lakes with areas larger than $100 \mathrm{~km}^{2}$ in this region. The total lake surface area is more than $21000 \mathrm{~km}^{2}$, which accounts for $25 \%$ of all water 
surface area of lakes in China and is one of the five largest lake groups in Asia (Wang et al. 2005). In 2005, CERN set up two stations in this region to measure systematically and continuously UV and global solar radiation. They are respectively Dong Lake (latitude $30^{\circ} 37^{\prime} \mathrm{N}$, longitude $114^{\circ} 21^{\prime} \mathrm{E}$, altitude $21 \mathrm{~m}$ ) and Tai Lake (latitude $31^{\circ} 25^{\prime} \mathrm{N}$, longitude $120^{\circ} 13^{\prime} \mathrm{E}$, altitude $10 \mathrm{~m}$ ), which are as shown in Fig. 1. Dong Lake (DL) is a medium sized urban freshwater lake in the northeastern part of Wuhan city with a surface area of $27.8 \mathrm{~km}^{2}$ and a mean depth of $3 \mathrm{~m}$. Tai Lake (TL) situated at Yangtze River Delta is the third largest freshwater lake in China, with an area of $2338 \mathrm{~km}^{2}$ and a mean depth of $1.89 \mathrm{~m}$ (Yao et al. 2009).

\subsection{Data Collection}

Radiation and relative humidity data used here are provided by CERN. Measurements of UV radiation (290 $400 \mathrm{~nm}$ ) are made by CUV3 radiometers with an accuracy of 5\% (Kipp \& Zonen, Delft, Netherlands). CM-11 pyranometers record global solar radiation $(305-2800 \mathrm{~nm})$ with an accuracy of $2-3 \%$ (Kipp \& Zonen, Delft, Netherlands). The relative humidity $(\mathrm{RH})$ of the atmosphere is measured by the HMP45D sensor (Vaisala, Finland) with an accuracy of $3 \%$ (Hu et al. 2007). All data are registered at 1-min intervals, and an hourly value is obtained by integrating the 1 -min values. The UV pyranometers are calibrated against a standard lamp. All CM-11 pyranometers are calibrated by the 'alternate method' (Forgan 1996). All instruments are calibrated and inter-compared during the period of the experiment to assure data quality.

UV and global solar radiation during the period from 2006 to 2007 are used here. To avoid problems associated with deviations by the measuring instrument from the ideal cosine law, the data analysis presented is limited to solar elevation angles greater than $10^{\circ}$ (Foyo-Moreno et al. 2007). In addition, a quality control is applied to the hourly UV and global solar radiation based on two main rules. At first,

Table 1. A symbol list in this text.

\begin{tabular}{|c|c|c|c|}
\hline \multicolumn{4}{|c|}{ Nomenclature } \\
\hline DL & Dong Lake & CERN & Chinese Ecosystem Research Network \\
\hline $\mathrm{TL}$ & Tai Lake & $\mathrm{m}$ & the relative optical air mass \\
\hline UV & ultraviolet radiation & $\mathrm{UV}_{\text {clear }}$ & UV under clear skies \\
\hline G & global solar radiation & $\mathrm{CAF}_{\text {UVclear }}$ & $\begin{array}{l}\text { the comprehensive attenuation factors for assumed } \\
\text { cloud-free conditions }\end{array}$ \\
\hline $\mathrm{K}_{\mathrm{g}}$ & global clearness index & model A & $\mathrm{UV}=\mathrm{hG}$ \\
\hline $\mathrm{K}_{\mathrm{UV}}$ & UV radiation transmissivity & model B & $\mathrm{K}_{\mathrm{UV}}=\mathrm{a} \cdot \mathrm{K}_{\mathrm{g}}^{\mathrm{b}} \cdot \mathrm{m}^{\mathrm{c}}$ \\
\hline $\mathrm{G}_{0}$ & extraterrestrial solar radiation & model C & $\mathrm{K}_{\mathrm{UV}}=\mathrm{d} \cdot \mathrm{CAF}_{\mathrm{UVclear}}^{\mathrm{e}} \cdot \mathrm{K}_{\mathrm{g}}^{\mathrm{f}}$ \\
\hline $\mathrm{UV}_{0}$ & extraterrestrial UV radiation & RMSE & root mean square error \\
\hline TOC & total ozone column & MABE & mean absolute bias error \\
\hline SOC & slant ozone column & MBE & mean bias error \\
\hline API & Air pollution index & $\mathrm{R}^{2}$ & the coefficient of determination \\
\hline
\end{tabular}

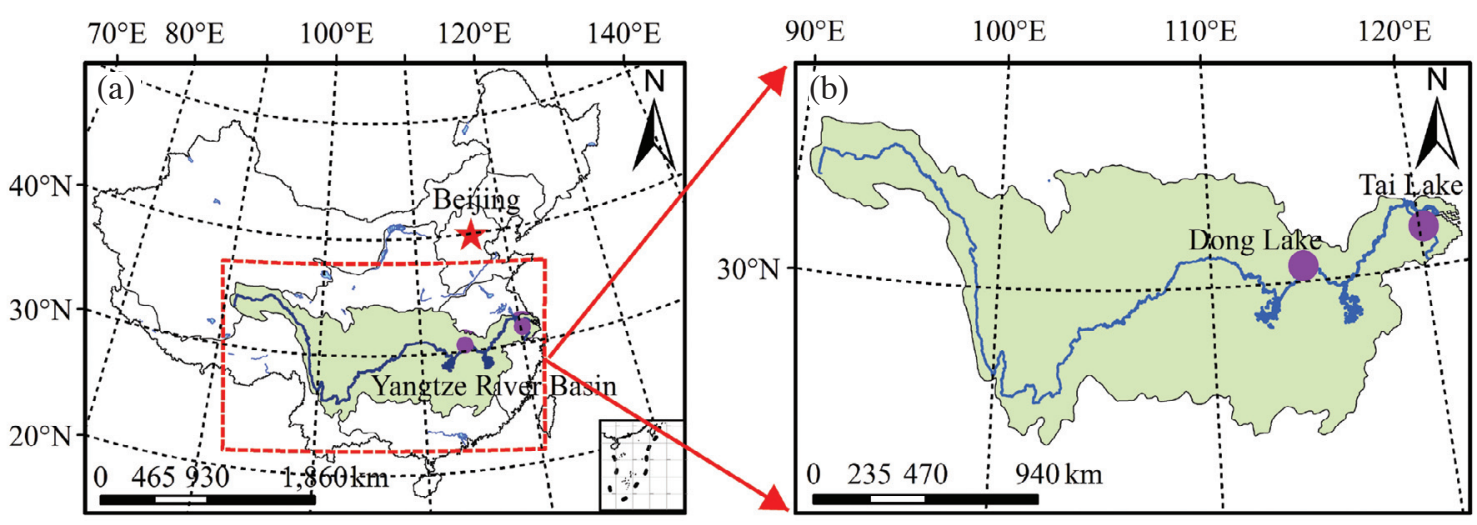

Fig. 1. Geographic position of the Yangtze River basin in China (a) and the locations of DL and TL in the Yangtze River basin (b). 
the measured UV radiation should be less than the extraterrestrial UV radiation, and the ratio UV to global solar radiation should be restricted to fluctuate from 0.02 to 0.08 (Hu et al. 2007). If not, the data are marked as problematic and eliminated from the data set. Secondly, the observed global solar radiation should be less than the extraterrestrial solar radiation and the ratio of surface solar radiation to the extraterrestrial solar radiation should be no less than 0.03 (Geiger et al. 2002).

Once the hourly radiation values are obtained, several parameters can be calculated. The first is the hourly UV radiation transmissivity $\mathrm{K}_{\mathrm{UV}}$, which is defined as:

$\mathrm{K}_{\mathrm{UV}}=\mathrm{UV} / \mathrm{UV}_{0}$

where UV is the measured hourly UV radiation, $\mathrm{UV}_{0}$ is the hourly extraterrestrial UV radiation (Mateos Villán et al. 2010; Podstawczyńska 2010).

Another evaluated parameter is the hourly global clearness index $\mathrm{K}_{\mathrm{g}}$, which is defined as:

$\mathrm{K}_{\mathrm{g}}=\mathrm{G} / \mathrm{G}_{0}$

where $G$ is the measured hourly global solar radiation. $G_{0}$ is the hourly extraterrestrial solar radiation (Antón et al. 2009a; Podstawczyńska 2010). The global clearness index $\mathrm{K}_{\mathrm{g}}$ is chosen to characterize the effect of clouds. This variable has been broadly used for its objective (Foyo-Moreno et al. 1999; Cañada et al. 2000; Ogunjobi and Kim 2004).

$\mathrm{G}_{0}$ and $\mathrm{UV}_{0}$ are calculated as:

$$
\begin{aligned}
\mathrm{X}_{0}= & \mathrm{I}_{\mathrm{SC}}(\mathrm{X}) \mathrm{E}_{0}[\sin \varphi \sin \delta+(24 / \pi) \sin (24 / \pi) \\
& \left.\cos \varphi \cos \delta \cos \omega_{\mathrm{i}}\right]
\end{aligned}
$$

where $I_{\mathrm{SC}}(\mathrm{X})$ is the integrated value of solar radiation in the selected band $\left[\mathrm{X}=\mathrm{UV}: \mathrm{I}_{\mathrm{sC}}(\mathrm{UV})=388.8 \mathrm{~kJ} \mathrm{~m}^{-2}\right.$ ] (Thekaekara 1973; Gueymard 2004; Mateos Villán et al. 2010; Podstawczyńska 2010). $\mathrm{E}_{0}$ is the correction to the sun-earth distance, $\omega_{\mathrm{i}}$ is the hourly angle in the middle of the hour, $\varphi$ is the latitude and $\delta$ is the solar declination.

The total ozone column (TOC) data are obtained from the Ozone Monitoring Instrument (OMI). OMI has been in operation since July 2004, which is a Dutch-Finnish contribution to the NASA EOS-Aura platform (Badarinath et al. 2008). It is a nadir-viewing spectrometer that measures reflected and backscattered solar UV and visible light (Levelt et al. 2006). It is a new generation of UV-visible spaceborne spectrometers which use two-dimensional detectors. These detectors enable OMI fit for monitoring atmospheric ozone, clouds, aerosols, $\mathrm{SO}_{2}, \mathrm{NO}_{2}, \mathrm{HCHO}, \mathrm{OClO}$, and $\mathrm{BrO}$. The spatial resolution of the instrument is $13 \times 24 \mathrm{~km}$ in nadir, and increases towards the edges of the swath to 13 $\times 150 \mathrm{~km}$. The total ozone column from OMI, expressed in Dobson Units (DU), is available at the NASA website http://aura.gsfc.nasa.gov/instruments/omi/index.html.

The air pollution index (API) is an index of environmental pollution based on the welfare losses associated with damages from exposure to pollution (Khanna 2000). Compared with the EPA's Pollutant Standards Index (PSI), API can furnish a detailed ranking by index value which would affect the implementation of an environmental policy that distributes resources to alleviate pollution. In addition, the API can better reflect the damage of the air pollution to the human than PSI in some cases. The main reason for the difference is that the API value is based on the ambient concentrations of all pollutants whereas PSI values are determined entirely by the gas with the highest relative concentration. The API measures daily air pollution levels due to the three gases: large particulate matter $\left(\mathrm{PM}_{10}\right)$, sulphur dioxide $\left(\mathrm{SO}_{2}\right)$ and nitrogen dioxide $\left(\mathrm{NO}_{2}\right)$. The API is available at the Ministry of Environmental Protection of the People's Republic of China website http://www.zhb.gov.cn.

\subsection{Model Validation}

The two year hourly data are divided into two groups. One group, comprised of $75 \%$ of all the data (randomly chosen), is used for constructing models (construction database) and the remaining data is used for validating the models (validation database) (Xia et al. 2008).

The models are validated with a root mean square error (RMSE), mean absolute bias error (MABE) and mean bias error (MBE) (Bilbao and de Miguel 2010; Mateos Villán et al. 2010). They are calculated as:

$\operatorname{RMSE}=\frac{100}{\bar{M}} \sqrt{\frac{\sum_{i=1}^{n}\left(M_{i}-E_{i}\right)^{2}}{n}}$

MABE $=\frac{100}{\bar{M}} \frac{\sum_{i=1}^{n}\left|M_{i}-E_{i}\right|}{n}$

$\mathrm{MBE}=\frac{100}{\overline{\mathrm{M}}}\left[\frac{\sum_{\mathrm{i}=1}^{\mathrm{n}}\left(\mathrm{M}_{\mathrm{i}}-\mathrm{E}_{\mathrm{i}}\right)}{\mathrm{n}}\right]$

where $\mathrm{M}_{\mathrm{i}}$ and $\mathrm{E}_{\mathrm{i}}$ are measured and estimated UV radiation, respectively, $\bar{M}$ is the mean of measured UV radiation, $n$ is the number of observed UV radiation used for validation.

The validation is conducted in two stages. First, the models are validated using the data from the same datasets used for model calibration (75\% for model calibration and $25 \%$ for model validation). In order to compare the applicability of different models to estimate UV in different envi- 
ronments, the models are validated using the data from different datasets. The models calibrated using the data from DL will be validated using the data from TL, vice versa.

\section{RESULTS AND DISCUSSION}

\subsection{Statistical Analysis of Values of UV Radiation in the Two Lakes}

\subsubsection{Statistical Analysis of Hourly Average Values of UV Radiation in the Two Lakes}

The characteristics of hourly UV radiation for each month are analyzed using the following statistical indices, an arithmetic mean (M), standard deviation (SD), median (Md), skewness (Ske), kurtosis (Kur), minimum value (Min), maximum value (Max), the first (Q1) and third (Q3) quartiles, inter-quartile range $(\mathrm{Q} 3-\mathrm{Q} 1)$, the $5^{\text {th }}(\mathrm{P} 5)$ and $95^{\text {th }}$ (P95) percentiles, variation coefficient $(\mathrm{CV}=100 \times \mathrm{SD} / \mathrm{M})$. As an example, Tables 2 and 3 show the results for August in years 2006 and 2007 at two stations (where $\mathrm{N}$ represents the sample number). It can be concluded that:

(1) The differences between the first quartile and the minimum values increase steadily from morning hours reaching the highest values at hours around midday. In some cases the first quartile could be up to $300 \%$ higher than the minima. The differences between the P5 percentile and the minimum values are fairly high, and the P5 could be sometimes up to $100 \%$ higher than the minima. These results indicate that the minimum values are not proper indicators of UV radiation for two lakes. The abnormally low values of the minima could be due to overcast skies. Similar result has been found by other researchers in Valencia (Cañada et al. 2008).

(2) The maximum values of UV radiation vary from $10.8 \mathrm{~kJ} \mathrm{~m}^{-2}$ in May to $180.0 \mathrm{~kJ} \mathrm{~m}^{-2}$ in July for DL and between $14.4 \mathrm{~kJ} \mathrm{~m}^{-2}$ in April and $225 \mathrm{~kJ} \mathrm{~m}^{-2}$ in June for TL.
The differences of UV radiation between the maximum values and the P95 percentile or the third quartile are generally fairly small for the two stations. These results mean that the maximum values can be representative of the UV radiation characteristics for both places, especially for clear days.

(3) The median values are different from the arithmetic mean values, and the absolute values of skewness and kurtosis are always not equal to zero, which suggest that the distribution of the measured hourly UV radiation at the two stations is not a normal distribution. But the absolute values of skewness and kurtosis are close to zero, and the median and the arithmetic mean values are reasonably similar with little difference.

(4) The standard deviation values of UV radiation are not high compared with the mean, although they increase towards the middle hours of the day for both stations, when the radiation shows higher values.

(5) The stability of UV radiation can be evaluated by means of the CV (\%) index. It can be seen that the stability of $\mathrm{UV}$ radiation is not symmetrical with respect to midday around the year. August represents the highest stability with the lowest values of $\mathrm{CV}$ that range between $22.39 \%$ and $35.31 \%$ for DL and from $22.47 \%$ to $43.87 \%$ for TL. The minimum stability occurs in February for DL with CV values from $43.58 \%$ to $66.25 \%$ and in January for TL with CV values from $23.81 \%$ to $61.70 \%$.

\subsubsection{Statistical Analysis of Monthly Mean Values of UV Radiation in the Two Lakes}

Figure 2 shows the daily evolution of the monthly mean values of the hourly UV radiation. It can be concluded that: (1) the maxima of monthly mean values occur at solar noon and the minima in the extreme hours (the beginning and the end of the day) at the two stations. For DL, the

Table 2. Characteristics of the hourly UV radiation $\left(\mathrm{kJ} \mathrm{m}^{-2}\right)$ at DL for August during 2006 - 2007.

\begin{tabular}{cccccccccccccccc}
\hline Hour & $\mathbf{N}$ & $\mathbf{M}$ & SD & Md & Ske & Kur & Min & Max & Q1 & Q3 & Q3 - Q1 & P5 & P95 & CV $(\%)$ \\
\hline 7 & 54 & 15.49 & 4.73 & 15.48 & 0.04 & -0.14 & 5.76 & 27.36 & 12.60 & 18.09 & 5.49 & 7.02 & 23.13 & 30.54 \\
8 & 58 & 35.86 & 9.91 & 39.24 & -1.06 & 0.25 & 9.72 & 48.60 & 29.43 & 43.20 & 13.77 & 15.21 & 46.85 & 27.63 \\
9 & 59 & 59.49 & 17.51 & 61.92 & -0.91 & 0.28 & 8.64 & 88.56 & 52.20 & 73.80 & 21.60 & 25.56 & 81.36 & 29.44 \\
10 & 62 & 80.29 & 25.60 & 87.30 & -1.29 & 1.09 & 12.96 & 119.52 & 70.29 & 98.28 & 27.99 & 15.84 & 107.53 & 31.88 \\
11 & 62 & 101.19 & 31.90 & 111.78 & -1.19 & 1.28 & 9.00 & 149.04 & 80.28 & 124.29 & 44.01 & 16.24 & 141.88 & 31.52 \\
12 & 62 & 107.16 & 37.83 & 127.44 & -0.77 & -0.60 & 15.12 & 161.64 & 75.42 & 135.54 & 60.12 & 35.44 & 148.05 & 35.31 \\
13 & 60 & 107.75 & 34.35 & 117.72 & -0.81 & -0.44 & 29.16 & 153.00 & 87.84 & 135.63 & 47.79 & 35.78 & 146.50 & 31.88 \\
14 & 62 & 93.57 & 28.86 & 97.02 & -0.54 & -0.53 & 24.12 & 137.16 & 74.52 & 117.63 & 43.11 & 41.56 & 132.41 & 30.84 \\
15 & 61 & 78.03 & 26.24 & 82.44 & -0.70 & -0.15 & 19.44 & 117.00 & 61.20 & 98.10 & 36.90 & 20.20 & 115.88 & 33.63 \\
16 & 61 & 56.63 & 19.55 & 61.56 & -0.73 & -0.23 & 13.68 & 88.56 & 44.64 & 72.36 & 27.72 & 15.77 & 83.95 & 34.53 \\
17 & 58 & 35.53 & 7.96 & 36.54 & -0.13 & -1.36 & 20.16 & 48.60 & 27.00 & 43.29 & 16.29 & 24.10 & 46.87 & 22.39 \\
\hline
\end{tabular}


Table 3. Characteristics of the hourly UV radiation $\left(\mathrm{kJ} \mathrm{m}^{-2}\right)$ at TL for August during 2006 - 2007.

\begin{tabular}{ccccccccccccccccc}
\hline Hour & $\mathbf{N}$ & $\mathbf{M}$ & $\mathbf{S D}$ & $\mathbf{M d}$ & Ske & Kur & Min & Max & Q1 & Q3 & Q3 - Q1 & P5 & P95 & CV (\%) \\
\hline 6 & 28 & 11.85 & 2.66 & 12.06 & -0.20 & -0.80 & 6.84 & 16.56 & 9.27 & 14.04 & 4.77 & 7.00 & 16.40 & 22.47 \\
7 & 53 & 34.49 & 7.99 & 35.28 & -0.88 & 2.15 & 7.56 & 51.84 & 31.86 & 39.06 & 7.20 & 17.24 & 47.70 & 23.16 \\
8 & 57 & 65.94 & 18.82 & 66.24 & -0.28 & -0.62 & 21.96 & 99.36 & 54.90 & 82.44 & 27.54 & 32.72 & 92.56 & 28.54 \\
9 & 59 & 100.89 & 29.90 & 107.28 & -1.06 & 1.20 & 9.00 & 159.84 & 84.24 & 120.96 & 36.72 & 33.84 & 133.56 & 29.63 \\
10 & 58 & 132.72 & 36.16 & 147.42 & -1.11 & 0.74 & 23.76 & 187.92 & 106.56 & 156.51 & 49.95 & 56.66 & 173.23 & 27.25 \\
11 & 57 & 147.13 & 42.98 & 158.04 & -1.19 & 1.16 & 9.00 & 213.12 & 135.36 & 174.96 & 39.60 & 58.64 & 198.68 & 29.21 \\
12 & 59 & 150.69 & 42.80 & 168.48 & -0.84 & -0.32 & 49.32 & 212.76 & 117.72 & 182.16 & 64.44 & 61.56 & 202.68 & 28.40 \\
13 & 60 & 150.75 & 36.93 & 159.30 & -1.16 & 1.02 & 43.92 & 209.88 & 133.65 & 174.60 & 40.95 & 78.30 & 197.89 & 24.50 \\
14 & 60 & 120.94 & 44.81 & 137.34 & -0.93 & -0.17 & 8.64 & 175.32 & 90.09 & 154.71 & 64.62 & 35.71 & 173.79 & 37.05 \\
15 & 56 & 99.55 & 33.94 & 106.56 & -1.04 & 0.47 & 9.36 & 147.24 & 72.81 & 126.27 & 53.46 & 15.84 & 140.98 & 34.10 \\
16 & 57 & 63.57 & 23.36 & 66.24 & -0.41 & -0.75 & 9.00 & 105.48 & 42.30 & 84.06 & 41.76 & 19.33 & 93.89 & 36.74 \\
17 & 52 & 32.65 & 14.32 & 34.20 & 0.05 & -0.86 & 7.56 & 60.12 & 21.51 & 43.56 & 22.05 & 9.70 & 57.02 & 43.87 \\
\hline
\end{tabular}
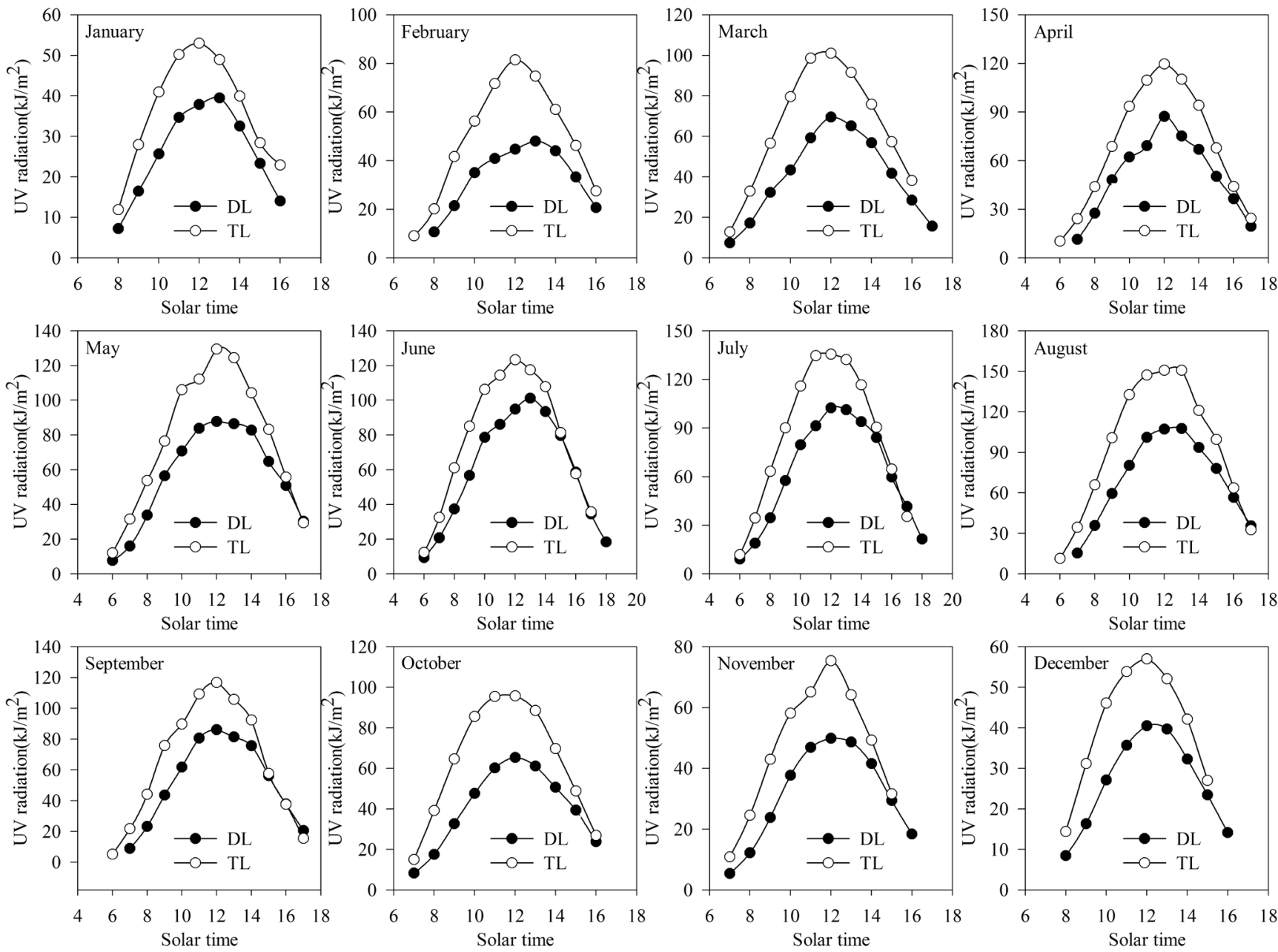

Fig. 2. Daily evolution of the monthly mean hourly UV radiation (in $\mathrm{kJ} \mathrm{m}^{-2}$ ) at DL and TL. 
maxima of monthly mean values fluctuate from $39.46 \mathrm{~kJ} \mathrm{~m}^{-2}$ in January to $107.66 \mathrm{~kJ} \mathrm{~m}^{-2}$ in August, respectively. For TL, the maximum values vary from $52.99 \mathrm{~kJ} \mathrm{~m}^{-2}$ in January to $150.81 \mathrm{~kJ} \mathrm{~m}^{-2}$ in August. (2) For each hour of the day, the highest values occur in August and the lowest in January or December for two stations. (3) The monthly mean values at TL ascend in the morning and descend in the afternoon much more quickly than those at DL. The values at TL for all hours are almost greater than those at DL. Furthermore, the differences in the monthly mean values increase steadily from morning hours reaching the highest values at around midday. These results can be attributed to the differences in the air pollution over the two lakes. The annual mean daily API values are 87.22 for DL and 68.83 for TL, respectively. The higher air pollution at DL leads to the higher depletion of UV by scattering and absorption than those at TL (Varotsos et al. 1995). Additionally, TL is the third largest freshwater lake in China, and its surface area is more than 84 times bigger than that of DL. The surface water temperature at TL has been warmed more slowly than that at DL by global solar radiation. The surface wind speeds above TL are greater than those above DL. The air pollution is carried away faster by winds above TL than those above DL (Desai et al. 2009). The complex effects of the air pollution and solar elevation angle on UV radiation results in the differences of the daily evolution of the monthly mean hourly UV radiation between the two sites.

Figure 3 shows the monthly mean hourly values for UV radiation and UV fraction at two stations. Table 4 presents the monthly mean values of global clearness index $\left(\mathrm{M}_{\mathrm{Kg}}\right)$, API $\left(\mathrm{M}_{\mathrm{API}}\right)$, total ozone column $\left(\mathrm{M}_{\mathrm{O} 3}\right)$ and $\mathrm{RH}\left(\mathrm{M}_{\mathrm{RH}}\right)$ at two stations. An analysis of $\mathrm{K}_{\mathrm{g}}, \mathrm{API}$, ozone and $\mathrm{RH}$ is performed in order to study the climatic and atmospheric conditions for the two sites. The minimum monthly means of hourly UV radiation appear in January with values of $25.68 \mathrm{~kJ} \mathrm{~m}^{-2}$ for DL and $36.00 \mathrm{~kJ} \mathrm{~m}^{-2}$ for TL. The maxima occur in August with values of $70.07 \mathrm{~kJ} \mathrm{~m}^{-2}$ for $\mathrm{DL}$ and $92.62 \mathrm{~kJ} \mathrm{~m}^{-2}$ for TL. The decrease of monthly surface UV radiation in June and July is due to an increase of precipitation and clouds produced by the rainy season (Meiyu) in the Yangtze River area. The clearness index $\mathrm{K}_{\mathrm{g}}$ provides a measure of clouds. The highest $\mathrm{K}_{\mathrm{g}}$ values occur in August for both stations, and the lowest correspond to January. In all months, UV is higher at TL than those at DL. The biggest difference of UV between the two sites appears in March. This may be attributed to the diversity in the atmospheric conditions between the two sites. The monthly mean API ranges between 61.33 in July and 106.39 in January at DL, but at TL from 48.69 in July to 91.43 in December. The monthly mean ozone fluctuates from 269.98 DU in October to 309.29 DU in April at DL, but at TL between 272.90 DU in October and 324.92 DU in April. The API at TL for each month is lower than that at DL, and the total ozone column at TL is slightly higher than that at DL. Although total column ozone and UV radiation are inversely related, the complex effects of API and ozone produce higher values of UV radiation at TL than those at DL.

The monthly means of hourly UV fractions range from $3.79 \%$ in November to $4.93 \%$ in July with an average of $4.22 \%$ at DL while these values vary from $4.57 \%$ in January and $5.94 \%$ in July with an average of $5.17 \%$ at TL. The UV fractions at the two sites are in the ranges of UV fractions reported elsewhere previously. UV radiation accounted for $4.4-5.6 \%$ of global solar radiation at various subartic locations in Nordic countries (Kvifte et al. 1983), $3.0-5.0 \%$ at Granada (Foyo-Moreno et al. 1998), 4.4 - 5.6\% at Valencia (Cañada et al. 2003), 3.9 - 5.0\% in Lhasa (Hu et al. 2008), $3.7-4.6 \%$ in Haibei (Hu et al. 2008).

Figure 3 also indicates there is an increasing trend in the UV fractions during the summer months for two stations, which is mainly attributed to the variation of precipitation and API. There are no obvious differences in RH and total ozone column between the summer season and other seasons. But, there is larger precipitation and lower API in this season compared with other seasons. The API values are lower due to wet decomposition effects caused by the
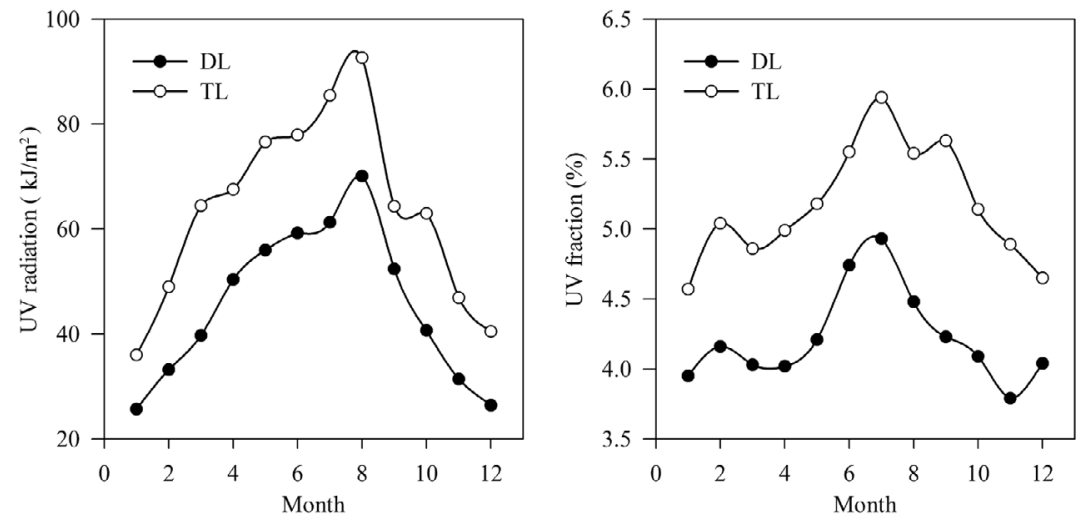

Fig. 3. The monthly mean hourly values for UV radiation (in $\mathrm{kJ} \mathrm{m}^{-2}$ ) and $\mathrm{UV}$ fraction (\%) at DL and TL. 
Table 4. Monthly mean values of $\mathrm{K}_{\mathrm{g}}$, API ozone and RH at DL and TL.

\begin{tabular}{|c|c|c|c|c|c|c|c|c|c|c|c|c|c|}
\hline Station & Index & January & February & March & April & May & June & July & August & September & October & November & December \\
\hline \multirow{4}{*}{ DL } & $\mathrm{M}_{\mathrm{Kg}}$ & 0.34 & 0.33 & 0.37 & 0.40 & 0.42 & 0.41 & 0.41 & 0.47 & 0.42 & 0.39 & 0.41 & 0.35 \\
\hline & $\mathrm{M}_{\mathrm{API}}$ & 106.39 & 83.02 & 93.67 & 87.03 & 91.48 & 75.18 & 61.33 & 69.19 & 79.41 & 94.97 & 99.10 & 105.88 \\
\hline & $\mathrm{M}_{\mathrm{O} 3}$ & 277.30 & 284.01 & 297.85 & 309.29 & 307.43 & 304.19 & 288.80 & 290.47 & 283.98 & 269.98 & 274.58 & 270.76 \\
\hline & $\mathrm{M}_{\mathrm{RH}}$ & 71.65 & 73.08 & 71.01 & 69.32 & 68.05 & 67.98 & 67.98 & 68.03 & 67.54 & 67.55 & 67.44 & 67.48 \\
\hline \multirow{4}{*}{ TL } & $\mathrm{M}_{\mathrm{Kg}}$ & 0.39 & 0.44 & 0.45 & 0.46 & 0.45 & 0.41 & 0.43 & 0.52 & 0.43 & 0.46 & 0.44 & 0.42 \\
\hline & $\mathrm{M}_{\mathrm{API}}$ & 72.46 & 61.88 & 70.89 & 75.14 & 69.30 & 57.07 & 48.69 & 50.51 & 67.51 & 74.53 & 86.57 & 91.43 \\
\hline & $\mathrm{M}_{\mathrm{O} 3}$ & 284.72 & 291.32 & 305.94 & 324.92 & 314.45 & 317.55 & 292.07 & 292.99 & 286.7 & 272.9 & 276.31 & 278.02 \\
\hline & $\mathbf{M}_{\mathrm{RH}}$ & 76.40 & 74.25 & 71.86 & 70.32 & 69.80 & 70.75 & 71.63 & 71.54 & 72.08 & 72.17 & 71.95 & 72.00 \\
\hline
\end{tabular}

increased precipitation produced by the Meiyu weather in this period. The scattering and absorption effects of air pollution on the UV radiation are lower in this period than other periods, which results in an increase in the UV fractions during the summer period.

In addition, the monthly means hourly UV radiation fractions at TL are always greater than those at DL, which are mainly due to higher water vapor and lower API. The RH ranges between $67.44 \%$ in November and $73.08 \%$ in February with an average of $68.92 \%$ at DL. For TL, the RH varies from $69.80 \%$ in May to $76.40 \%$ in January with an average of $72.06 \%$. The absorption of global solar radiation by water vapor in the atmosphere is greater in the near infrared region of the spectrum than in the UV wavelength band (Jacovides et al. 2006). The higher water vapor leads to the larger extinction of global solar radiation than that of UV radiation. The higher API leads to the higher extinction of UV than that of global solar radiation. The higher water vapor and lower API at TL can cause the higher UV fractions than those at DL, though total ozone column at TL is slightly higher than that at DL.

\subsection{Innovative UV Estimation Model for All Weather Conditions}

In order to demonstrate the effectiveness of the new model developed here, two reported statistical models are assessed. One model empirically estimates UV radiation from global solar radiation $(\mathrm{G})$ as reported in extensive literature (Cañada et al. 2003; Ogunjobi and Kim 2004; Escobedo et al. 2009, 2011). The empirical model has advantages of simple use and dependence only on global solar radiation and is widely available. This model is expressed as:

$$
\mathrm{UV}=\mathrm{hG}
$$

where $\mathrm{h}$ is the fit coefficient, UV is the measured hourly
$\mathrm{UV}$ radiation $\left(\mathrm{kJ} \mathrm{m}^{-2}\right), \mathrm{G}$ is the measured hourly global solar radiation $\left(\mathrm{kJ} \mathrm{m}^{-2}\right)$. This model is named as model A.

The parameter $\mathrm{h}$ in model A needs to be calibrated using in situ measurements. The use of model A should be restricted to the particular site where it is obtained. Noting that nondimensional parameters may be less influenced by the local features, recent studies on modeling the hourly UV radiation values have been based on UV radiation transmissivity $\mathrm{K}_{\mathrm{UV}}$. UV radiation transmissivity $\mathrm{K}_{\mathrm{UV}}$ is selected as a dependent variable, which has the great advantage because its changes can be exclusively attributed to atmospheric attenuation factors. Several authors have proposed different models that link the hourly UV radiation transmissivity $\mathrm{K}_{\mathrm{UV}}$ with its main attenuation factors, such as cloudiness (through global clearness index) and relative optical air mass (FoyoMoreno et al. 1999; Martínez-Lozano et al. 1999; Cañada et al. 2003; Ogunjobi and Kim 2004; Varo et al. 2005; Barbero et al. 2006; Hu et al. 2010; Mateos Villán et al. 2010). Barbero's model has been used in this paper:

$\mathrm{K}_{\mathrm{UV}}=\mathrm{a} \cdot \mathrm{K}_{\mathrm{g}}^{\mathrm{b}} \cdot \mathrm{m}^{\mathrm{c}}$

where $\mathrm{a}, \mathrm{b}, \mathrm{c}$ are the coefficients, $\mathrm{K}_{\mathrm{UV}}$ is hourly $\mathrm{UV}$ radiation transmissivity, $\mathrm{K}_{\mathrm{g}}$ is hourly global clearness index, and $\mathrm{m}$ is relative optical air mass. This model represents model B.

The relative optical air mass $\mathrm{m}$ in Eq. (8) is calculated as (Kasten and Young 1989):

$\mathrm{m}=1 /\left[\cos \theta_{z}+0.050572\left(96.0795-\theta_{z}\right)^{-1.6364}\right]$

where $\theta_{z}$ is the solar zenith angle expressed in degrees.

However, only the solar elevation angle and cloudiness in model B are considered to characterize the attenuation effects of UV radiation through the atmosphere. The amounts of the UV radiation reaching the earth's surface are also modulated by other attenuation factors, such as air pollution 
and ozone, which have a certain effect on the UV radiation. An innovative UV estimation model is proposed in this paper to quantify the resultant effects of all the attenuation factors for all weather conditions. The resulting effects of all the attenuation factors on UV radiation can be considered to consist of two parts: the effect of the comprehensive attenuation factors for assumed cloud-free conditions $\left(\mathrm{CAF}_{\mathrm{UV} \text { clear }}\right)$ and the effect of the clouds (through the global clearness index $\mathrm{K}_{\mathrm{g}}$ ). The best relationship among $\mathrm{K}_{\mathrm{UV}}, \mathrm{CAF}_{\mathrm{UV} \text { clear }}$ and $\mathrm{K}_{\mathrm{g}}$ is given in the following equation that constitutes model $\mathrm{C}$ :

$\mathrm{K}_{\mathrm{UV}}=\mathrm{d} \cdot \mathrm{CAF}_{\mathrm{UVclear}}{ }^{\mathrm{e}} \cdot \mathrm{K}_{\mathrm{g}}^{\mathrm{f}}$

where $\mathrm{d}$, e and $\mathrm{f}$ are the coefficients.

In a similar way to the $\mathrm{K}_{\mathrm{UV}}$ definition, the effect of the comprehensive attenuation factors for assumed cloud-free conditions $\left(\mathrm{CAF}_{\mathrm{UVclear}}\right)$ in Eq. (10) can be defined as the ratio of surface UV under clear skies to extraterrestrial UV radiation:

$\mathrm{CAF}_{\mathrm{UV} \text { clear }}=\mathrm{UV}_{\text {clear }} / \mathrm{UV}_{0}$

Surface UV under clear skies $\left(\mathrm{UV}_{\text {clear }}\right)$ can be estimated by any radiative transfer model or empirical model. The relative optical air mass and ozone are easily available and are the two main attenuation factors affecting surface UV radiation under clear skies (Kerr and McElroy 1995; Rieder et al. 2008). In this study, $\mathbf{U V}_{\text {clear }}$ is derived from empirical models based on relative optical air mass or ozone.

Total ozone column (TOC) strongly absorbs UV radiation and has significant effects on the amount of UV reaching the surface. The hourly actual ozone amount crossed through by the solar radiation in the atmosphere is the slant ozone column (SOC) defined as (Antón et al. 2008):
$\mathrm{SOC}=\frac{\mathrm{TOC}}{\cos \theta_{z}}$

where $\theta_{z}$ is the solar zenith angle expressed in degrees.

\subsection{Comparison of Three Models Estimating UV Radia- tion}

\subsubsection{Presented Model for Estimating UV Radiation Under Different Weather Conditions/Previous Models for All Weather Conditions}

Changes of UV radiation with the relative optical air mass (m) and slant ozone column (SOC) are shown in Figs. 4 and 5. UV radiation decreases with increases in relative optical air mass or slant ozone column, although with high dispersion. However, the relative optical air mass or slant ozone column alone cannot estimate UV radiation with satisfactory accuracy.

UV observations under clear skies $(\mathrm{kg}>0.75)$ in years 2006 and 2007 are selected from the UV radiation dataset. Figures 4 and 5 also show the dependence of UV radiation values under clear skies (black points) on the relative optical air mass or slant ozone column and it can be seen that the obtained dispersion is now smaller than when all conditions are considered (grey points). The UV radiation values under clear skies $\left(\mathrm{UV}_{\text {clear }}\right)$ can be modeled as a function of relative optical air mass or slant ozone column. Here, $75 \%$ of them are used to construct models for estimating UV radiation under clear skies $\left(\mathrm{UV}_{\text {clear }}\right)$ from relative air mass or slant ozone column. The remaining data of UV radiation under clear skies are used for model validations.

The relationships among $\mathrm{m}$, slant ozone column and UV radiation under clear skies have been established as the following Eqs. (13) - (18). Table 5 shows the results obtained for the two stations including $\mathrm{R}^{2}$, RMSE, MABE and MBE.
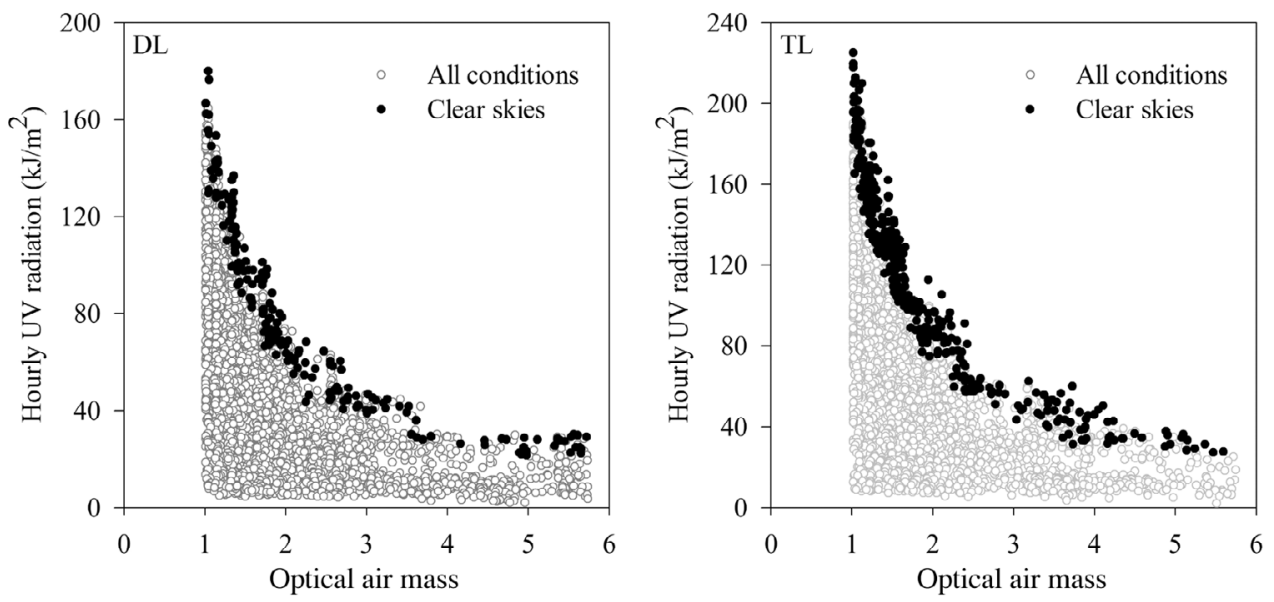

Fig. 4. Dependence of hourly UV radiation values $\left(\mathrm{kJ} \mathrm{m}^{-2}\right)$ on relative optical air mass under clear skies (black points) and all (grey points) conditions over the two lakes. 

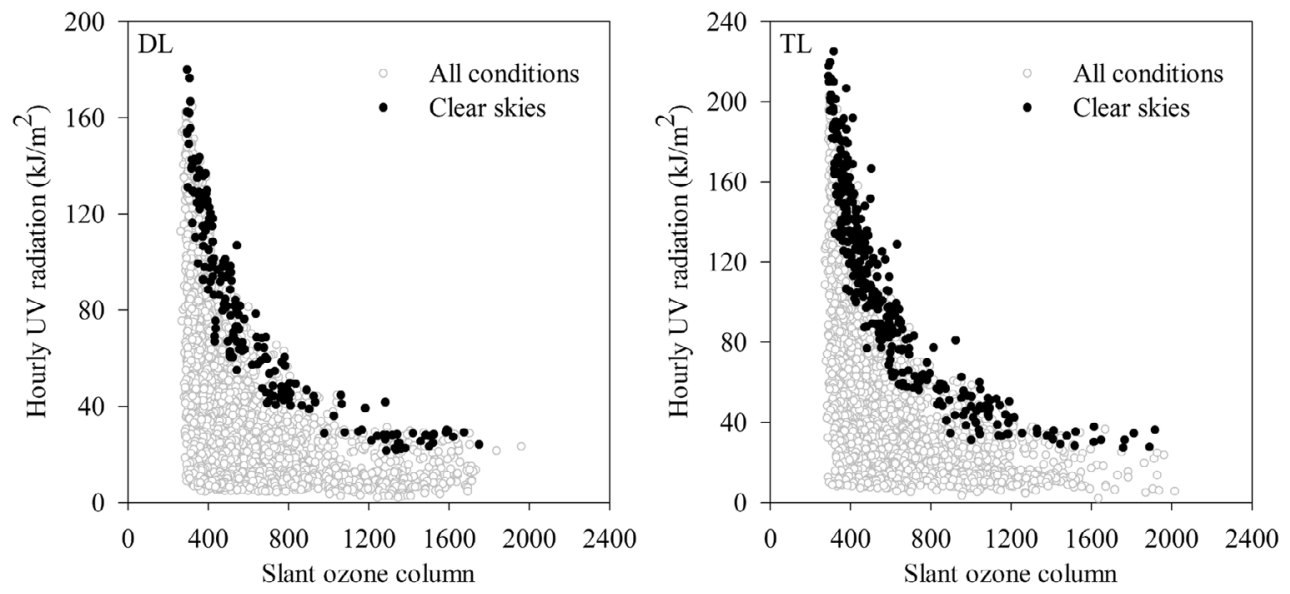

Fig. 5. Dependence of hourly UV radiation values $\left(\mathrm{kJ} \mathrm{m}^{-2}\right)$ on the slant ozone column under clear skies (black points) and all (grey points) conditions over the two lakes.

Table 5. Results of Eqs. (13) - (18) for DL and TL.

\begin{tabular}{cccccc}
\hline Station & Equation & $\mathbf{R}^{2}$ & RMSE $(\%)$ & MABE $(\%)$ & MBE $(\%)$ \\
\hline DL & 13 & 0.96 & 10.40 & 7.94 & $-2.66 \mathrm{e}-2$ \\
TL & 14 & 0.95 & 9.35 & 7.24 & $-1.26 \mathrm{e}-2$ \\
DL & 15 & 0.92 & 14.12 & 10.90 & $-2.41 \mathrm{e}-11$ \\
TL & 16 & 0.91 & 13.41 & 9.87 & $-5.78 \mathrm{e}-7$ \\
DL & 17 & 0.96 & 10.37 & 7.92 & $-4.16 \mathrm{e}-5$ \\
TL & 18 & 0.96 & 9.17 & 7.04 & $-3.63 \mathrm{e}-5$ \\
\hline
\end{tabular}

DL: $\mathrm{UV}_{\text {clear }}=3.6437+97.5881 / \mathrm{m}+66.0451 / \mathrm{m}^{2}$

TL: $\mathrm{UV}_{\text {clear }}=2.0117+136.1014 / \mathrm{m}+66.0648 / \mathrm{m}^{2}$

DL: $\mathrm{UV}_{\text {clear }}=3.3675+29209.3455 / \mathrm{SOC}$

$$
+4966828.9518 / \mathrm{SOC}^{2}
$$

TL: $\mathrm{UV}_{\text {clear }}=-1.3258+45807.9561 / \mathrm{SOC}$

$$
+4380307.4919 / \mathrm{SOC}^{2}
$$

DL: $\mathrm{UV}_{\text {clear }}=4.2933+139.3086 / \mathrm{m}+29.7684 / \mathrm{m}^{2}$

$$
\text { - } 12801.4189 / \mathrm{SOC}+3211882.8902 / \mathrm{SOC}^{2}
$$

TL: $\mathrm{UV}_{\text {clear }}=3.6634+203.5754 / \mathrm{m}-1.5673 / \mathrm{m}^{2}$

$$
-22469.0544 / \mathrm{SOC}+6708022.0131 / \mathrm{SOC}^{2}
$$

Equations (13) - (18) are validated using the remaining $25 \%$ of UV observations under clear skies. Linear regression analysis between estimated and measured values of UV radiation under clear skies is carried out. Table 6 shows the assessed results for Eqs. (13) - (18) including slope j, intercept $k$, and $\mathrm{R}^{2}$ of the linear regression of estimated versus measured UV radiation under clear skies, as well as RMSE, MABE and MBE. Equations (15) and (16) based on the slant ozone column give the highest RMSE and MABE values, Eqs. (13) and (14) take the second place, and Eqs. (17) and (18) provide the lowest values. It means that Eqs. (17) and (18) based on relative optical air mass and slant ozone column are slightly better than the others. Equations (17) and (18) have been selected to calculate the effect of the comprehensive attenuation factors for assumed cloud-free conditions of each hour $\left(\mathrm{CAF}_{\text {UVclear }}\right)$ in model $\mathrm{C}$.

Models A, B and C are performed with the constructed database explained in section 2 in order to calculate the coefficients of the models. Table 7 shows the results for the two stations including the coefficients of the models, $\mathrm{R}^{2}$, RMSE, MABE and MBE.

The three models are assessed with the validation database as explained in section 2. Linear regression analysis between estimated and measured values of UV radiation is carried out for the three models. Table 8 shows a summary of the assessed results for different models including slope 1 , intercept $n$, and $R^{2}$ of the linear regression of estimated 
Table 6. Results of the validations analysis of Eqs. (13) - (18) for DL and TL.

\begin{tabular}{cccccccc}
\hline Station & Equation & Slope $\mathbf{j}$ & Intercept $\mathbf{k}$ & $\mathbf{R}^{2}$ & RMSE (\%) & MABE (\%) & MBE (\%) \\
\hline DL & 13 & 0.9704 & 3.3473 & 0.97 & 8.67 & 6.84 & 1.18 \\
TL & 14 & 1.0020 & -0.3962 & 0.95 & 9.65 & 7.15 & -0.15 \\
DL & 15 & 0.9881 & 2.7844 & 0.95 & 12.08 & 9.61 & 2.25 \\
TL & 16 & 1.0215 & -0.4642 & 0.89 & 14.86 & 10.77 & 1.69 \\
DL & 17 & 0.9705 & 3.3633 & 0.97 & 8.54 & 6.58 & 1.21 \\
TL & 18 & 1.0123 & -1.2440 & 0.96 & 9.35 & 6.94 & 0.10 \\
\hline
\end{tabular}

Table 7. The parameter values of the three models for DL and TL.

\begin{tabular}{|c|c|c|c|c|c|c|c|c|c|c|c|c|}
\hline & Model & h & $\mathbf{a}$ & b & c & D & e & f & $\mathbf{R}^{2}$ & RMSE (\%) & MABE (\%) & MBE (\%) \\
\hline DL & A & 0.0392 & - & - & - & - & - & - & 0.98 & 18.85 & 14.42 & 1.18 \\
\hline $\mathrm{TL}$ & A & 0.0494 & - & - & - & - & - & - & 0.98 & 16.82 & 13.22 & 1.04 \\
\hline DL & B & - & 0.4424 & 0.8080 & -0.1040 & - & - & - & 0.91 & 17.01 & 13.23 & 1.54 \\
\hline $\mathrm{TL}$ & B & & 0.5937 & 0.8276 & -0.1692 & - & - & - & 0.92 & 14.39 & 11.21 & 0.90 \\
\hline DL & $\mathrm{C}$ & - & - & - & - & 0.8881 & 0.8033 & 0.7669 & 0.91 & 16.28 & 12.55 & 1.42 \\
\hline $\mathrm{TL}$ & $\mathrm{C}$ & - & - & - & - & 1.1948 & 0.8249 & 1.0314 & 0.93 & 13.87 & 10.73 & 0.81 \\
\hline
\end{tabular}

Table 8. Summary with the assessed results of the three models for DL and TL.

\begin{tabular}{cccccccc}
\hline Station & Model & $\mathbf{l}$ & $\mathbf{n}$ & $\mathbf{R}^{2}$ & RMSE (\%) & MABE (\%) & MBE (\%) \\
\hline DL & A & 0.9647 & 2.0937 & 0.93 & 18.52 & 14.39 & 0.71 \\
TL & A & 0.9798 & 2.2982 & 0.94 & 16.82 & 13.12 & 1.26 \\
DL & B & 1.0032 & 0.0016 & 0.90 & 16.95 & 13.07 & 1.14 \\
TL & B & 0.9871 & 0.0059 & 0.91 & 14.44 & 11.15 & 0.89 \\
DL & C & 0.9991 & 0.0020 & 0.90 & 16.23 & 12.42 & 0.96 \\
TL & C & 0.9845 & 0.0061 & 0.92 & 13.86 & 10.63 & 0.69 \\
\hline
\end{tabular}

versus measured UV radiation, as well as RMSE, MABE and MBE. These results indicate that: (1) the three models can provide acceptable estimates of hourly surface UV radiation and can be used to calculate hourly UV radiation when no UV observations are available, and (2) model A gives the highest RMSE and MABE values, model B takes the second place, and model $\mathrm{C}$ provides the lowest values. Model B slightly improves the estimates by model A for both stations. However, model $\mathrm{C}$ is slightly better than the others for both stations.

\subsubsection{Applicability of Different Models for UV Estima- tion}

In order to compare the applicability of the three mod- els to estimate UV in different environments, the models are validated using the data from different datasets. The models calibrated using data from DL will be validated using data from TL, vice versa. Table 9 shows the assessed results for applicability of different models including slope $\mathrm{p}$, intercept $\mathrm{q}$, and $\mathrm{R}^{2}$ of the linear regression of estimated versus measured UV radiation, as well as RMSE, MABE and MBE. It can be observed that model A gives the highest RMSE values for DL and TL, model B takes the second place, and model $\mathrm{C}$ provides the lowest values. The new model clearly improves the estimates by the two reported models at a different locality. This means that model $\mathrm{C}$ can provide satisfactory estimates of UV radiation at a different locality other than the local place of origin where the relationships are developed. 
Huang et al.

Table 9. The assessed results for applicability of different models for UV estimation.

\begin{tabular}{cccccccc}
\hline Station & Model & $\mathbf{p}$ & $\mathbf{q}$ & $\mathbf{R}^{2}$ & $\mathbf{R M S E}(\%)$ & MABE (\%) & MBE (\%) \\
\hline \multirow{2}{*}{ DL } & A from TL & 0.7716 & 1.8792 & 0.93 & 37.19 & 28.26 & 24.68 \\
& B from TL & 0.7681 & 0.0062 & 0.90 & 34.38 & 28.18 & -26.03 \\
& C from TL & 0.9564 & 0.0070 & 0.91 & 16.31 & 12.52 & -0.79 \\
\cline { 4 - 6 } & A from DL & 1.2330 & 2.2775 & 0.94 & 29.85 & 22.51 & -21.52 \\
& B from DL & 1.3067 & -0.0028 & 0.90 & 29.04 & 23.65 & 22.69 \\
& C from DL & 1.1031 & -0.0026 & 0.91 & 16.94 & 13.15 & 8.50 \\
\hline
\end{tabular}

It indicates that the new proposed method can be used to estimate UV radiation at a different locality from only two input parameters: the effect of the comprehensive attenuation factors for assumed cloud-free conditions and the effect of the clouds. The first input parameter is easily derived from the radiative transfer model or empirical approach. The second one can be calculated by global solar radiation, which is usually available at most radiometric station.

\section{CONCLUSIONS}

A statistical analysis of hourly and monthly UV radiation at two typical sites (DL and TL) in the middle and lower reaches of Yangtz River has been described. Moreover, an innovative model suitable for estimating UV radiation under different weather conditions has been developed. The ability of different models to estimate UV radiation has been evaluated. From this study, following conclusions can be drawn:

(1) With respect to the hourly average UV radiation, the analysis indicates that the maximum values can represent the hourly UV characteristics for both stations, whereas the minima are not proper indicators. The median and the arithmetic mean values are reasonably similar with little difference. The CV parameters present that the stability of UV radiation is not symmetrical with respect to midday around the year. The highest stability of UV radiation corresponds to August for two stations, and the minimum stability occurs in February for DL and in January for TL.

(2) From the analysis of monthly mean UV radiation, it peaks at solar noon and shrinks in hours close to sunset and sunrise for the two stations. For each hour of the day, the highest values occur in August and the lowest in January or December. The values at TL for all hours are almost always greater than those at DL. The minimum monthly means of hourly UV radiation appear in January with values of $25.68 \mathrm{~kJ} \mathrm{~m}^{-2}$ for DL and $36.00 \mathrm{~kJ} \mathrm{~m}^{-2}$ for TL. The maxima occur in August with values of 70.07 $\mathrm{kJ} \mathrm{m}^{-2}$ for DL and $92.62 \mathrm{~kJ} \mathrm{~m}^{-2}$ for TL. In all months,
UV is higher at TL than that at DL. The monthly mean hourly UV radiation fractions range from $3.79 \%$ in November to $4.93 \%$ in July with an average of $4.22 \%$ at DL, but at TL they vary between $4.57 \%$ in January and $5.94 \%$ in July with an average of $5.17 \%$. The UV radiation fractions at TL are always greater than those at DL.

(3) The innovative UV estimation model is constructed based on two input parameters: the effect of the comprehensive attenuation factors for assumed cloud-free conditions and the effect of the clouds. The innovative model presents values of RMSE better than two reported models either at local place or a different locality. It indicates that the new model can provide satisfactory estimates of UV radiation at a different locality other than the local place where the relationships of origin are developed.

Acknowledgements The study is funded by the State Key Fundamental Science Funds of China (2010CB950702, 2010CB428503, 2005CB422207, and 2005CB422208), State Key International Cooperation Project (200073819), the State High Technology Funds of China (2009AA122001 and 2009AA122005), the State Data Synthesis and Analysis Funds of China (2007FY110300-08), NSF-China Project (40671132), and the key project of Zhejiang Province (2008C13G2100010), and Scientific Research Foundation of Graduate School of Nanjing University (2009CL07). Many thanks are given to the Dong Lake and Tai Lake observation team in the Chinese Ecosystem Research Network for their hard work in collecting data. The authors would like to thank the two reviewers for their comments.

\section{REFERENCES}

Al-Aruri, S., M. Rasas, K. Al-Jamal, and N. Shaban, 1988: An assessment of global ultraviolet solar radiaiton in the range (0.290-0.380 $\mu \mathrm{m})$ in Kuwait. Sol. Energy, 41, 159-162, doi: 10.1016/0038-092X(88)90132-6. [Link]

Antón, M., M. Cancillo, A. Serrano, and J. A. García, 2005: A multiple regression analysis between UV radiation measurements at Badajoz and ozone, reflectivity and 
aerosols estimated by TOMS. Phys. Scr., T118, 21-23, doi: 10.1238/Physica.Topical.118a00021. [Link]

Antón, M., A. Serrano, M. L. Cancillo, and J.A. García, 2008: Relationship between erythemal irradiance and total solar irradiance in South-Western Spain. J. Geophys. Res., 113, 1-7, doi: 10.1029/2007JD009627. [Link]

Antón, M., A. Serrano, M. L. Cancillo, and J. A. García, 2009a: An empirical model to estimate ultraviolet erythemal transmissivity. Ann. Geophys., 27, 1387-1398, doi: 10.5194/angeo-27-1387-2009. [Link]

Antón, M., A. Serrano, M. L. Cancillo, and J. A. García, 2009b: Influence of the relative optical air mass on ultraviolet erythemal irradiance. J. Atmos. Sol.-Terr. Phys.,71,2027-2031,doi: 10.1016/j.jastp.2009.09.009. [Link]

Badarinath, K. V. S., S. K. Kharol, V. K. Prasad, A. R. Sharma, E. U. B. Reddi, H. D. Kambezidis, and D. G. Kaskaoutis, 2008: Influence of natural and anthropogenic activities on UV Index variations - a study over tropical urban region using ground based observations and satellite data. J. Atmos. Chem., 59, 219-236, doi: 10.1007/s10874-008-9103-4. [Link]

Bais, A. F., C. S. Zerefos, C. Meleti, I. C. Ziomas, and K. Tourpali, 1993: Spectral measurements of solar UVB radiaiton and its relations to total ozone, $\mathrm{SO}_{2}$, and clouds. J. Geophys. Res., 98, 5199-5204, doi: 10.1029/ 92JD02904. [Link]

Barbero, F. J., G. López, and F. J. Batlles, 2006: Determination of daily solar ultraviolet radiation using statistical models and artificial neural networks. Ann. Geophys., 24, 2105-2114, doi: 10.5194/angeo-24-21 05-2006. [Link]

Bartlett, L. M. and A. R. Webb, 2000: Changes in ultraviolet radiation in the 1990s: Spectral measurements from Reading, England. J. Geophys. Res., 105, 4889-4893, doi: 10.1029/1999JD900493. [Link]

Bhattarai, B. K., B. Kjeldstad, T. M. Thorseth, and A. Bagheri, 2007: Erythemal dose in Kathmandu, Nepal based on solar UV measurements from multichannel filter radiometer, its deviation from satellite and radiative transfer simulations. Atmos. Res., 85, 112-119, doi: 10.1016/j.atmosres.2006.11.006. [Link]

Bilbao, J. and A. de Miguel, 2010: Estimation of UV-B irradiation from total global solar meteorological data in central Spain. J. Geophys. Res., 115, D00I09, 1-10, doi: 10.1029/2009JD012505. [Link]

Cañada, J., G. Pedrós, A. López, and J. V. Boscá, 2000: Influences of the clearness index for the whole spectrum and of the relative optical air mass on UV solar irradiance for two locations in the Mediterranean area, Valencia and Cordoba. J. Geophys. Res., 105, 47594766, doi: 10.1029/1999JD901106. [Link]

Cañada, J., G. Pedrós, and J. V. Boscá, 2003: Relationships between UV $(0.290-0.385 \mu \mathrm{m})$ and broad band solar radiation hourly values in Valencia and Córdoba, Spain. Energy, 28, 199-217, doi: 10.1016/S0360-5442 (02)00111-1. [Link]

Cañada, J., A. R. Esteve, M. J. Marín, M. P. Utrillas, F. Tena, and J. A. Martínez-Lozano, 2008: Study of erythemal, UV $(\mathrm{A}+\mathrm{B})$ and global solar radiation in Valencia (Spain). Int. J. Climatol., 28, 693-702, doi: 10.1002/joc.1569. [Link]

Carrillo, P., J. A. Delgado-Molina, J. M. Medina-Sánchez, F. J. Bullejos, and M. Villar-Argaiz, 2008: Phosphorus inputs unmask negative effects of ultraviolet radiation on algae in a high mountain lake. Global Change Biol., 14, 423-439, doi: 10.1111/j.1365-2486.2007.01496.x. [Link]

Clair, T. A., J. Ehrman, I. Kaczmarska, A. Locke, D. W. Tarasick, K. E. Day, and G. Maillet, 2001: Will reduced summer UV-B levels affect zooplankton populations of temperate humic and clearwater lakes? Hydrobiologia, 462, 75-89, doi: 10.1023/A:1013128202565. [Link]

Cordero, R. R., P. Roth, A. Georgiev, and L. DaSilva, 2005: Climatology of surface ultraviolet-radiation in Valparaiso, Chile. Energy Conv. Manag., 46, 2907-2918, doi: 10.1016/j.enconman.2005.02.008. [Link]

Cui, X., S. Gu, X. Zhao, J. Wu, T. Kato, and Y. Tang, 2008: Diurnal and seasonal variations of UV radiation on the northern edge of the Qinghai-Tibetan Plateau. $A g$ ric. For. Meteorol., 148, 144-151, doi: 10.1016/j.agrformet.2007.09.008. [Link]

de La Casinière, A., M. L. Touré, D. Masserot, T. Cabot, and J. L. P. Vega, 2002: Daily doses of biologically active UV radiation retrieved from commonly available parameters. Photochem. Photobiol., 76, 171-175, doi: 10.1562/0031-8655(2002)0760171DDOBAU2.0. CO2. [Link]

den Outer, P. N., H. Slaper, and R. B. Tax, 2005: UV radiation in the Netherlands: Assessing long-term variability and trends in relation to ozone and clouds. J. Geophys. Res., 110, D02203, doi: 10.1029/2004JD004824. [Link]

Desai, A. R., J. A. Austin, V. Bennington, and G. A. McKinley, 2009: Stronger winds over a large lake in response to weakening air-to-lake temperature gradient. Nat. Geosci., 2, 855-858, doi: 10.1038/ngeo693. [Link]

Díaz, S., G. Deferrari, D. Martinioni, and A. Oberto, 2000: Regression analysis of biologically effective integrated irradiances versus ozone, clouds and geometric factors. J. Atmos. Sol.-Terr. Phys., 62, 629-638, doi: 10.1016/ S1364-6826(00)00055-9. [Link]

Dubrovsky, M., 2000: Analysis of UV-B irradiances measured simultaneously at two stations in the Czech Republic. J. Geophys. Res., 105, 4907-4913, doi: 10.1029/ 1999JD900374. [Link]

Escobedo, J. F., E. N. Gomes, A. P. Oliveira, and J. Soares, 2009: Modeling hourly and daily fractions of UV, PAR 
and NIR to global solar radiation under various sky conditions at Botucatu, Brazil. Appl. Energy, 86, 299309, doi: 10.1016/j.apenergy.2008.04.013. [Link]

Escobedo, J. F., E. N. Gomes, A. P. Oliveira, and J. Soares, 2011: Ratios of UV, PAR and NIR components to global solar radiation measured at Botucatu site in Brazil. Renew. Energy, 36, 169-178, doi: 10.1016/j.renene. 2010.06.018. [Link]

Feister, U. and K. H. Grasnick, 1992: Solar UV radiation measurements at potsdam $\left(52^{\circ} 22^{\prime} \mathrm{N}, 13^{\circ} 5^{\prime} \mathrm{E}\right)$. Sol. Energy, 49, 541-548, doi: 10.1016/0038-092X(92)901 62-4. [Link]

Feister, U. and R. Grewe, 1995: Higher UV radiation inferred from low ozone levels at northern midlatitudes in 1992 and 1993. Global Planet. Change, 11, 25-34, doi: 10.1016/0921-8181(94)00013-4. [Link]

Fioletov, V. E., L. J. B. McArthur, J. B. Kerr, and D. I. Wardle, 2001: Long-term variations of UV-B irradiance over Canada estimated from Brewer observations and derived from ozone and pyranometer measurements. J. Geophys. Res., 106, 23009-23027, doi: 10.1029/2001JD000367. [Link]

Fioletov, V. E., J. B. Kerr, D. I. Wardle, N. Krotkov, and J. R. Herman, 2002: Comparison of Brewer ultraviolet irradiance measurements with total ozone mapping spectrometer satellite retrievals. Opt. Eng., 41, 3051, doi: 10.1117/1.1516818. [Link]

Forgan, B. W., 1996: A new method for calibrating reference and field pyranometers. J. Atmos. Ocean. Technol., 13, 638-645, doi: 10.1175/1520-0426(1996)013< 0638:ANMFCR>2.0.CO;2. [Link]

Foyo-Moreno, I., J. Vida, and L. Alados-Arboledas, 1998: Ground based ultraviolet (290-385 nm) and broadband solar radiation measurements in south-eastern Spain. Int. J. Climatol., 18, 1389-1400, doi: 10.1002/ (SICI)1097-0088(1998100)18:12<1389::AID-JOC3 18>3.0.CO;2-N. [Link]

Foyo-Moreno, I., J. Vida, and L. Alados-Arboledas, 1999: A simple all weather model to estimate ultraviolet solar radiation (290-385 nm). J. Appl. Meteorol., 38, 10201026, doi: 10.1175/1520-0450(1999)038<1020:ASAW MT>2.0.CO;2. [Link]

Foyo-Moreno, I., I. Alados, and L. Alados-Arboledas, 2007: Adaptation of an empirical model for erythemal ultraviolet irradiance. Ann. Geophys., 25, 1499-1508, doi: 10.5194/angeo-25-1499-2007. [Link]

Geiger,M.,L.Diabaté,L. Ménard, and L. Wald, 2002: A web service for controlling the quality of measurements of global solar irradiation. Sol. Energy, 73, 475-480, doi: 10.1016/S0038-092X(02)00121-4. [Link]

Gröbner, J., M. Blumthaler, S. Kazadzis, A. Bais, A. Webb, J. Schreder, G. Seckmeyer, and D. Rembges, 2006: Quality assurance of spectral solar UV measurements: Results from 25 UV monitoring sites in Europe, 2002 to 2004. Metrologia, 43, S66-S71, doi: 10.1088/00261394/43/2/s14. [Link]

Gueymard, C. A., 2004: The sun's total and spectral irradiance for solar energy applications and solar radiation models. Sol. Energy, 76, 423-453, doi: 10.1016/j. solener.2003.08.039. [Link]

Gurney, K. R., 1998: Evidence for increasing ultraviolet irradiance at Point Barrow, Alaska. Geophys. Res. Lett., 25, 903-906, doi: 10.1029/98GL00405. [Link]

Harrison, J. W. and R. E. H. Smith, 2009: Effects of ultraviolet radiation on the productivity and composition of freshwater phytoplankton communities. Photochem. Photobiol. Sci., 8, 1218-1232, doi: 10.1039/b902604e. [Link]

Hu, B., Y. Wang, and G. Liu, 2007: Ultraviolet radiation spatio-temporal characteristics derived from the groundbased measurements taken in China. Atmos. Environ., 41, 5707-5718, doi: 10.1016/j.atmosenv.2007.02.044. [Link]

Hu, B., Y. Wang, and G. Liu, 2008: Influences of the Clearness Index on UV Solar Radiation for Two Locations in the Tibetan Plateau-Lhasa and Haibei. Adv. Atmos. Sci., 25, 885-896, doi: 10.1007/s00376-008-0885-8. [Link]

Hu, B., Y. Wang, and G. Liu, 2010: Variation characteristics of ultraviolet radiation derived from measurement and reconstruction in Beijing, China. Tellus Ser. B-Chem. Phys. Meteorol., 62, 100-108, doi: 10.1111/j.1600-08 89.2010.00452.x. [Link]

Ilyas, M., A. Pandy, and S. I. S. Hassan, 1999: UV-B radiation at Penang. Atmos. Res., 51, 141-152, doi: 10.1016/ S0169-8095(99)00005-8. [Link]

Jacovides, C. P., V. D. Assimakopoulos, F. S. Tymvios, K. Theophilou, and D. N. Asimakopoulos, 2006: Solar global UV (280-380 $\mathrm{nm}$ ) radiation and its relationship with solar global radiation measured on the island of Cyprus. Energy, 31, 2728-2738, doi: 10.1016/j.energy. 2005.11.021. [Link]

Janjai, S., S. Buntung, R. Wattan, and I. Masiri, 2010: Mapping solar ultraviolet radiation from satellite data in a tropical environment. Remote Sens. Environ., 114, 682-691, doi: 10.1016/j.rse.2009.11.008. [Link]

Junk, J., U. Feister, and A. Helbig, 2007: Reconstruction of daily solar UV irradiation from 1893 to 2002 in Potsdam, Germany. Int. J. Biometeorol., 51, 505-512, doi: 10.1007/s00484-007-0089-4. [Link]

Kasten, F. and A. T. Young, 1989: Revised optical air mass tables and approximation formula. Appl. Optics, 28, 4735-4738, doi: 10.1364/AO.28.004735. [Link]

Kerr, J. B. and C. T. McElroy, 1995: Total ozone measurements made with the Brewer ozone spectrophotometer during STOIC 1989. J. Geophys. Res., 100, 9225-9230, doi: 10.1029/94JD02147. [Link]

Khanna, N., 2000: Measuring environmental quality: An in- 
dex of pollution. Ecol. Econ., 35, 191-202, doi: 10.10 16/S0921-8009(00)00197-X. [Link]

Koepke, P., 2009: Radiative models for the evaluation of the UV radiation at the ground. Radiat. Prot. Dosim., 137, 188-192, doi: 10.1093/rpd/ncp211. [Link]

Krzyścin, J. W., J. Jarosławski, and P. Sobolewski, 2001: On an improvement of UV index forecast: UV index diagnosis and forecast for Belsk, Poland, in Spring/Summer 1999. J. Atmos. Sol.-Terr. Phys., 63, 1593-1600, doi: 10.1016/S1364-6826(01)00041-4. [Link]

Kudish, A. I. and E. Evseev, 2000: Statistical relationships between solar UVB and UVA radiation and global radiation measurements at two sites in Israel. Int. J. Climatol., 20, 759-770, doi: 10.1002/1097-0088(200 00615)20:7<759::AID-JOC494>3.0.CO;2-K. [Link]

Kvifte, G., K. Hegg, and V. Hansen, 1983: Spectral distribution of solar radiaiton in the Nordic countries. J. Clim. Appl. Meteorol., 22, 143-152, doi: 10.1175/1520-0450 (1983)022<0143:SDOSRI>2.0.CO;2. [Link]

Láska, K., P. Prošek, L. Budík, M. Budíková, and G. Milinevsky, 2010: Estimation of solar UV radiation in maritime Antarctica using a nonlinear model including cloud effects. Int. J. Remote Sens., 31, 831-849, doi: 10.1080/01431160902897866. [Link]

Levelt, P. F., G. H. J. van den Oord, M. R. Dobber, A. Malkki, H. Visser, J. de Vries, P. Stammes, J. O. V. Lundell, and H. Saari, 2006: The Ozone Monitoring Instrument. IEEE Trans. Geosci. Remote Sensing, 44, 1093-1101, doi: 10.1109/tgrs.2006.872333. [Link]

Liu, C. M., 2000: Surface erythemally-weighted UVB flux in Taiwan. Terr. Atmos. Ocean. Sci., 11, 879-894.

Madronich, S., 1992: Implications of recent total atmospheric ozone measurements for biologically active ultraviolet radiation reaching the earth's surface. Geophys. Res. Lett., 19, 37-40, doi: 10.1029/91GL02954. [Link]

Martínez-Lozano, J. A., F. Tena, and M. P. Utrillas, 1999: Ratio of UV to global broad band irradiation in Valencia, Spain. Int. J. Climatol., 19, 903-911, doi: 10.1002/ (SICI) 1097-0088(19990630)19:8<903::AID-JOC4 00>3.0.CO;2-N. [Link]

Mateos Villán, D., A. de Miguel Castrillo, and J. Bilbao Santos, 2010: Empirical models of UV total radiation and cloud effect study. Int.J.Climatol., 30, 1407-1415, doi: 10.1002/joc.1983. [Link]

McKenzie, R. L., W. A. Matthews, and P. V. Johnston, 1991: The relationship between erythemal UV and ozone, derived from spectral irradiance measurements. Geophys. Res. Lett., 18, 2269-2272, doi: 10.1029/91GL02786. [Link]

McKenzie, R. L., P. V. Johnston, M. Kotkamp, A. Bittar, and J. D. Hamlin, 1992: Solar ultraviolet spectroradiometry in New Zealand: Instrumentation and sample results from 1990. Appl. Optics, 31, 6501-6509, doi: 10.1364/AO.31.006501. [Link]
Murillo, W., J. Cañada, and G. Pedrós, 2003: Correlation between global ultraviolet (290-385 $\mathrm{nm}$ ) and global irradiation in Valencia and Cordoba (Spain). Renew. Energy, 28, 409-418, doi: 10.1016/S0960-1481(02)000 39-3. [Link]

Nazari, E. M., D. Ammar, A. F. de Bem, A. Latini, Y. M. R. Müller, and S. Allodi, 2010: Effects of environmental and artificial UV-B radiation on freshwater prawn Macrobrachium olfersi embryos. Aquat. Toxicol., 98, 25-33, doi: 10.1016/j.aquatox.2010.01.010. [Link]

Ogunjobi, K. O. and Y. J. Kim, 2004: Ultraviolet (0.280$0.400 \mu \mathrm{m})$ and broadband solar hourly radiation at Kwangju, South Korea: Analysis of their correlation with aerosol optical depth and clearness index. Atmos. Res.,71,193-214,doi:10.1016/j.atmosres.2004.05.001. [Link]

Pienitz, R. and W.F. Vincent, 2000: Effect of climate change relative to ozone depletion on UV exposure in subarctic lakes. Nature, 404, 484-487, doi: 10.1038/35006616. [Link]

Podstawczyńska, A., 2010: UV and global solar radiation in Łódź, Central Poland. Int. J. Climatol., 30, 1-10, doi: 10.1002/joc.1864. [Link]

Prasad, N. V. K. and K. Niranjan, 2005: Solar UV-B irradiance at a tropical Indian Station,Visakhapatnam $\left(17.70^{\circ}\right.$ North, $83.30^{\circ}$ East $)$ - A relation with TOMS ozone. Terr. Atmos. Ocean. Sci., 16, 215-229.

Ramirez Santigosa, L., J. Polo Martínez, L. Mora López, M. Sidrach de Cardona Ortin and J. Blanco Galvez, 2003: Fuzzy inference systems applied to the daily ultraviolet radiation evaluation $(295-385 \mathrm{~nm})$ from daily global radiation. Sol. Energy, 75, 447-454, doi: 10.1016/j. solener.2003.09.014. [Link]

Rieder, H. E., F. Holawe, S. Simic, M. Blumthaler, J. W. Krzyścin, J. Wagner, A. Schmalwieser, and P. Weihs, 2008: Reconstruction of erythemal UV-levels for two stations in Austria: A comparison between alpine and urban regions. Atmos. Chem. Phys. Discuss., 8, 957994, doi: 10.5194/acpd-8-957-2008. [Link]

Robaa, S. M., 2004: A study of ultraviolet solar radiation at Cairo urban area, Egypt. Sol. Energy, 77, 251-259, doi: 10.1016/j.solener.2004.01.008. [Link]

Sabziparvar, A. A., 2009: Estimation of clear-sky effective erythema radiation from broadband solar radiation (300-3000 nm) data in an arid climate. Int.J. Climatol., 29, 2027-2032, doi: 10.1002/joc.1848. [Link]

Salo, H. M., E. I. Jokinen, S. E. Markkula, T. M. Aaltonen, and H. T. Penttilä, 2000: Comparative effects of UVA and UVB irradiation on the immune system of fish. $J$. Photochem. Photobiol. B-Biol., 56, 154-162, doi: 10. 1016/S1011-1344(00)00072-5. [Link]

Schmalwieser, A. W., G. Schauberger, and M. Janouch, 2003: Temporal and spatial variability of total ozone content over Central Europe: analysis in respect to the 
biological effect on plants. Agric. For. Meteorol., 120, 9-26, doi: 10.1016/j.agrformet.2003.08.008. [Link]

Sommaruga, R., 2001: The role of solar UV radiation in the ecology of alpine lakes. J. Photochem. Photobiol. B-Biol., 62, 35-42, doi: 10.1016/S1011-1344(01)001 54-3. [Link]

Sommaruga, R. and R. Psenner, 1997: Ultraviolet radiation in a high mountain lake of the Austrian Alps: Air and underwater measurements. Photochem. Photobiol., 65, 957-963, doi: 10.1111/j.1751-1097.1997. tb07954.x. [Link]

Tarasick, D. W., V. E. Fioletov, D. I. Wardle, J. B. Kerr, L. J. B. McArthur, and C. A. McLinden, 2003: Climatology and trends of surface UV radiation: Survey article. Atmos.-Ocean, 41, 121-138, doi: 10.3137/ao.410202. [Link]

Thekaekara, M. P., 1973: Solar energy outside the earth's atmosphere. Sol.Energy, 14, 109-127, doi: 10.1016/00 38-092X(73)90028-5. [Link]

Varo, M., G. Pedrós, and P. Martínez-Jimenez, 2005: Modelling of broad band ultraviolet clearness index distributions for Cordoba, Spain. Agric. For. Meteorol., 135, 346-351, doi: 10.1016/j.agrformet.2005.11.008. [Link]

Varotsos, C. A., G. J. Chronopoulos, S. Katsikis, and N. K. Sakellariou, 1995: Further evidence of the role of air pollution on solar ultraviolet radiation reaching the ground. Int. J. Remote Sens., 16, 1883-1886, doi: 10. 1080/01431169508954525. [Link]

Wang, S., X. Jin, Y. Pang, H. Zhao, X. Zhou, and F. Wu, 2005: Phosphorus fractions and phosphate sorption characteristics in relation to the sediment compositions of shallow lakes in the middle and lower reaches of Yangtze River region, China. J. Colloid Interface Sci.,
289, 339-346, doi: 10.1016/j.jcis.2005.03.081. [Link]

Wrona, F. J., T. D. Prowse, J. D. Reist, J. E. Hobbie, L. M. J. Lévesque, R. W. Macdonald, and W. F. Vincent, 2006a: Effects of ultraviolet radiation and contaminant-related stressors on Arctic freshwater ecosystems. Ambio, 35, 388-401, doi: 10.1579/0044-7447(2006)35 [388:EOURAC]2.0.CO;2. [Link]

Wrona, F. J., T. D. Prowse, J. D. Reist, J. E. Hobbie, L. M. J. Lévesque, and W. F. Vincent, 2006b: Climate impacts on Arctic freshwater ecosystems and fisheries: Background, rationale and approach of the Arctic Climate Impact Assessment (ACIA). Ambio, 35, 326-329, doi: 10.1579/0044-7447(2006)35[326:CIOAFE]2.0.CO;2. [Link]

Xia, X., Z. Li, P. Wang, M. Cribb, H. Chen, and Y. Zhao, 2008: Analysis of relationships between ultraviolet radiation (295-385 nm) and aerosols as well as shortwave radiation in North China Plain. Ann. Geophys., 26, 2043-2052, doi: 10.5194/angeo-26-2043-2008. [Link]

Xiao, C., W. Dou, and G. Liu, 2010: Variation in vegetation and seed banks of freshwater lakes with contrasting intensity of aquaculture along the Yangtze River, China. Aquat. Bot., 92, 195-199, doi: 10.1016/j.aquabot.2009. 11.007. [Link]

Yao, S., B. Xue, W. Xia, Y. Zhu, and S. Li, 2009: Lead pollution recorded in sediments of three lakes located at the middle and lower Yangtze River basin, China. Quat. Int., 208, 145-150, doi: 10.1016/j.quaint.2008.10.013. [Link]

Zerefos, C. S., D. S. Balis, A. F. Bais, D. Gillotay, P. C. Simon, B. Mayer, and G. Seckmeyer, 1997: Variability of UV-B at four stations in Europe. Geophys. Res. Lett., 24, 1363-1366, doi: 10.1029/97GL01177. [Link] 